\title{
The Communication of Neurological Bad News to Parents
}

\author{
Mohammed M.S. Jan and John P. Girvin
}

\begin{abstract}
Communicating disappointing or unexpected neurological news to parents is often both difficult and emotionally unwelcome. At the same time, it is important that transfer of such information is done well and, indeed, if done well, can be a very rewarding experience. Limited references are available for physicians regarding the proper communication of neurological bad news to parents. This paper attempts to provide general guidelines regarding this process. The review is based on the available medical literature, detailed discussions with many senior physicians from different medical systems and the authors'personal experience. The manner in which neurological bad news is conveyed to parents can significantly influence their emotions, their beliefs and their attitudes towards the child, the medical staff, and the future. This review of the literature, combined with clinical experience, attests to the fact that most families describe emotional shock, upset, and subsequent depression after the breaking of news of a bad neurological disorder. However, the majority find the attitude of the news giver, combined with the clarity of the message and the news giver's knowledge to answer questions as the most important aspects of giving bad news.
\end{abstract}

RÉSUMÉ: La communication de mauvaises nouvelles aux parents en neuropédiatrie. Communiquer une nouvelle décevante ou inattendue aux parents est souvent difficile et lourde au point de vue émotif en neuropédiatrie. Il est important que le transfert d'une telle information soit bien fait et, si tel est le cas, peut être une expérience très gratifiante. Il existe peu de publications disponibles pour les médecins concernant la façon appropriée de communiquer de mauvaises nouvelles aux parents en neuropédiatrie. Cet article tente de fournir des lignes directrices générales sur ce sujet. La revue est basée sur la littérature médicale disponible, des discussions détaillées avec plusieurs médecins d'expérience travaillant dans différents systèmes médicaux et l'expérience personnelle des auteurs. La façon dont une mauvaise nouvelle neurologique est donnée aux parents peut influencer significativement leurs émotions, leurs croyances et leur attitude envers l'enfant, le personnel médical et l'avenir. Cette revue de la littérature, associée à l'expérience clinique, démontre que la plupart des familles décrivent un choc émotif, se sentent perturbées, puis déprimées après l'annonce d'une maladie neurologique sévère chez leur enfant. Cependant, la majorité considère que l'attitude du professionnel qui donne la nouvelle, la clarté du message et sa capacité à répondre aux questions sont les aspects les plus importants de cette démarche.

Can. J. Neurol. Sci. 2002; 29: 78-82

Many traumatic, infectious, vascular, and neoplastic neurological disorders carry poor prognoses for complete neurological recovery. These disorders may result in chronic disability with multiple medical and neurological complications. The common practice of consanguineous marriage in Saudi Arabia results in a high prevalence of many inherited and genetic neurological and metabolic disorders. ${ }^{1,2}$ Many of these children exhibit progressive deterioration in cognitive, language, and/or motor function. Because of the high incidence of such disorders, many of which cannot be characterized, the necessity of facing parents with discussions regarding prognosis is not uncommon.

Informing parents of the diagnosis of a chronic illness or disability in their child is a difficult task. At the same time, it is important that the informing is done well. How parents are told can significantly influence their emotions, beliefs, and their attitudes towards the child, medical staff, and future. Most families describe shock, the state of being upset, and subsequent depression after hearing the news of a bad neurological disorder such as neurofibromatosis. ${ }^{3}$ However, the attitude of the news giver, combined with the clarity of the message and the knowledge in providing answers to questions have been found to be important aspects of giving bad news. ${ }^{4}$ Most physicians are not well prepared to deal with communicating bad news as in their training they usually receive little or no formal education regarding the process. ${ }^{5}$ In a recent survey, while most young

From the Department of Neurosciences, King Faisal Specialist Hospital and Research Centre, Jeddah, Kingdom of Saudi Arabia.

ReCEIVED APRIL 27, 2001. ACCEPTEDIN FINALFORM OCTOBER 5, 2001. Reprint requests to: Mohammed M.S. Jan, Department of Neurosciences, King Faisal Specialist Hospital and Research Centre, MBC J-76, PO Box 40047, Jeddah 21499 , Saudi Arabia 
physicians wanted instructions on how to break bad news, only $45 \%$ had received any such instruction. ${ }^{6}$ Additionally it is accepted that many physicians are unaware of their difficulties in giving information in a clear and comprehensive way. ${ }^{7}$

Limited references are available for physicians regarding the proper communication of neurological bad news to parents. Most of the pertinent literature deals with death, malignancies, surgical procedures, or acute life threatening situations. The communication of serious problems in acute conditions differs quite considerably from chronic or progressive neurological conditions. This paper attempts to provide general guidelines regarding the process of communicating neurological bad news to parents. The review is based on the available medical literature, detailed discussions with many senior physicians from different medical systems, and the authors'personal experience. Opinions of different physicians (pediatricians, neurologists, and neurosurgeons) were gathered informally over many years of training and practice (discussions and observations during disclosures). This took place in different countries (Canada, Saudi Arabia, and England), settings (acute, chronic, medical, and surgical), time eras, and institutions. Our current work in the Neurosciences department combining neurology, neurosurgery, neurophysiology, and psychiatry adds further to our previous experiences. We deal with a wide variety of children with both acute and chronic, as well as both medical and surgical neurological disorders in a highly specialized tertiary care center, King Faisal Specialist Hospital and Research Center in Jeddah. This institution provides tertiary care to most of the regional population of western Saudi Arabia. Nearly all senior physicians are aware that communicating details of unfortunate, especially chronic or progressively deteriorating, neurological conditions to parents becomes easier and less emotionally distasteful with increased experience. It is the objective of this paper to attempt to capture such experience and articulate it in such a way that the younger clinicians can be the beneficiaries - at least to the point that the wheel does not need to be completely rediscovered by each individual facing the responsibility in early practice.

\section{Preparations FOR BREAKING NEUROLOGICAL BAD NEWS}

Physicians must prepare adequately for the process of communicating bad news. This process is not only stressful to parents but also to most physicians. ${ }^{8}$ The ideal would be that all physicians take an educational course that deals with breaking bad news. Several studies have documented that such educational programs provided to medical students, $, 9,10$ residents, ${ }^{11}$ or other physicians, ${ }^{12,13}$ improves their ability to council and inform parents. In one study, formal instructions improved the humanistic skills of the provider as they relate to the delivery of bad news. ${ }^{9}$ As well, most students involved in one program found it enjoyable, useful, and found that it increased their sense of competence and their ability to formulate a strategy for such situations. ${ }^{10}$ An educational program should teach the physician various methods of managing stress and crises intervention. The education should involve clarification of personal attitudes, discussion of previous personal encounters of the participants, examination of various communication modalities, analyses of different methods of addressing and understanding parents' feelings and emotions, and exposure to various coping skills in dealing with the emotions of the one breaking the bad news. ${ }^{13}$ If a formal educational program is not available to the physician, self-education and learning from the literature (such as this article) and sharing the experience of more senior physicians in the field can be helpful. Physicians must realize what impact the news can have on the parents, must overcome the potential fear of being blamed for the message, and must not accept a sense of failure for not being able to remedy or improve the natural history of a bad diagnosis. ${ }^{14}$

\section{Preparation for the INITIAL INTERVIEW}

The key for good communication is to prepare carefully for the initial interview. ${ }^{7}$ Adequate time must exist so that the meeting is not rushed. At least 30, and preferably 60 minutes should be reserved. The physician should know the child very well and should have at her/his fingertips all relevant medical facts. Detailed discussions with the other members of the team and consultants who evaluated the child are needed as part of the interview. The diagnosis should be adequately documented and pending results and their possible implications should be outlined. Reaching a specific diagnosis is of clear importance for providing appropriate therapy, prognosis, and genetic counseling. Computed tomography and MRI images could be used to illustrate any structural central nervous system abnormalities.

It is always helpful to find out how much the parents know or suspect before the meeting. Awareness of the family's dynamics and their socio-cultural expectations would further facilitate the physician's role and interactions during the initial interview. ${ }^{15}$ Arrangements should be made with both parents to attend the meeting. The common practice in Saudi Arabian culture of telling the father first and giving him the task of breaking the bad news to the family should probably be discouraged. Studies have documented that when parents are told together they derive support from each other. ${ }^{16}$ In this way, each parent will receive first hand information, will more likely remember what has been said, and will have a chance to ask questions. The presence of other extended relatives should be discouraged, at least in the initial instance. Certainly, there are often important support persons whom, by virtue of their relationship to the family, their stations in life, or their background education, the families may wish to have present at subsequent interviews. This is understandable and acceptable, however, it is our practice not to allow more than three family members in such meetings. It is optional to have the child present during the interview. We usually allow infants and younger children to attend, but discourage older children who may become unnecessarily exposed to poorly understood details and to their parent's emotional reactions.

\section{WHEN, WHERE, AND WHO SHOULD BREAK NEUROLOGICAL BAD} NEWS?

The neurological bad news should be communicated to the parents as soon as possible after medical investigation is confirmative and preferably before the child is discharged from hospital. The news should be given in person and never over the telephone. A comfortable meeting room to provide privacy in a friendly atmosphere is ideal. Preferably, the room should be away 
from the clinic or ward area to avoid distractions and allow no interruption. The consultant who knows the child best and is closest to the family is the one who should break the news. This is usually the pediatric neurologist or neurosurgeon. However, as alluded to earlier, if the family has a regular family physician in whom they have obvious confidence, it may be beneficial to have her/him participate in the interview. Selected members of the team may attend this meeting including the intern, resident, nurse, social worker, and other involved subspecialists. In order not to overwhelm the parents, we usually prefer the attendance of a maximum of four team members who know the child and the family best. All such members should have had good interactions with, and be well known to the family. One consultant should lead the interview and direct the discussion in order to provide consistency and continuity. Only in very exceptional circumstances should interns, residents, or nurses communicate neurological bad news. In one study, residents showed a general lack of competence in delivering bad news, particularly relating to the elicitation of the parent's perspectives, i.e. they lacked a patient centered interviewing style. ${ }^{17}$ This is perhaps predictable, given their limited experience which, of course, improves with increased training. In fact, we always encourage the junior members to attend these meetings as part of their learning experience.

\section{HOW TO BREAK NEUROLOGICAL BAD NEWS}

All parents are anxious during the initial interview, as more times than not they have some inkling that they are about to receive difficult-to-accept information about their child. The physician must exhibit maturity, friendliness, and firmness on the background of respect and trust. The literature would support the notion that most parents prefer communication of information and feelings by a physician who clearly possesses a deportment of confidence. ${ }^{18}$ Sharp and colleagues considered that their strongest preferences were for physicians to show caring, to allow parents to talk, and to allow parents to show their own feelings. ${ }^{18}$ The lead physician needs to introduce the members of the team attending the meeting. We always allow the parents to tell us what they already know about the child's condition and how they think he or she is doing. We frequently begin by saying, "What is your understanding of [your child's] condition?" This may ease their initial excessive anxiety, improve the interaction, and make the process easier as most parents have a good sense of the seriousness of their child's condition, as already noted. Further, and probably most importantly, it provides the best entrance into the discussion and there is no doubt about the fact that the most difficult part of such an interview is its initiation.

It is best if the information is given in small but balanced amounts. Staging the given information may be needed rather than presenting the parents with all the information at once. Start with general medical issues and then proceed to more difficult and specific prognostic information. The information should include the diagnosis, cause, features, complications, treatments, and prognosis. During the communication of the bad news, the provider should be open, frank, honest, and should maintain good eye contact. Explanations should be kept simple, direct, and at a level of understanding that is both clear to the parents and keep to a minimum any reference to medical jargon. However, the informational content and medical details can be expressed differently according to the parent's educational level. In this time era, many parents are knowledgeable and can handle complex medical information, particularly with the advent of the Internet resources.

Throughout the discussion, the balance between avoiding pessimism, providing hope, and being realistic needs to be maintained. Pointing out the child's strengths and weaknesses without false reassurance is needed. It is important to point out the remarkable ability of the developing central nervous system to adapt and recover following insults. It is important to emphasize that this "plasticity" of the brain can facilitate continuing recovery for several months to a year following any insult to the nervous system, e.g., such as in the case of trauma, vascular compromise, etc. We usually simplify this concept by stating that the undamaged areas of the brain can take over some of the functions of the damaged areas, as a means of emphasizing the concept of plasticity. Avoid overstating the possible improvements to prevent false hope of complete neurological recovery. Some parents have strong religious beliefs. Recognizing and understanding when strong religious faith prevails can be of immeasurable benefit with the appropriately placed emphasis. In Saudi Arabia for example, Moslems have faith in God and in life after death. Part of this faith is the acceptance that God's will is inevitable and the exact future is in his hands. This belief gives the parents internal satisfaction and happiness with the child's outcome as long as they are confident not only in their faith but also in the medical team.

Humor during the interview should be avoided because of possible misinterpretation by anxious parents. Sensitivity to both informational content and parents' responses and emotional reactions is critical. When bad news is broken insensitively, the impact can be distressing for both giver and recipient. ${ }^{14}$ For the recipient, especially, the effect can be long lasting. Years later, parents will continue to remember exactly who and how the bad news was conveyed. Allow both parents to ask questions, but maintain the direction of the discussion. Avoid discussing hypothetical questions or scenarios and promise the parents that problems and new issues will be discussed when they arise. We usually tell parents that more time is needed to clarify the course of each child's disease and we cannot always predict the future accurately. Avoid arguing with the parents and try your best to be both empathetic and supportive of their emotional responses. ${ }^{16}$ At some point during the final part of the discussion we usually indicate something like "We would rather not be in this position of having to confront you with this news, but this is where we are now, and this is the point from which we must proceed". Assure them that there will be future meetings, more than one if necessary, to discuss the child's problems in more detail and answer any new questions which might arise. Advise the parents to write a list of questions that they may have in the near future for the next meeting. At the end of the interview, the physician should leave and give the parents time together in the room. This is especially important after the initial interview.

\section{REPEATED INTERVIEWS}

Sequential interviews usually are best conducted by the same provider for continuity of care and consistency of the given message. Again, the parents must be allowed to update you with the child's condition. Confidence in their ability to cope with and 
manage the child must be conveyed to them. The information given in the first meeting should be summarized and then expanded, updated and further questions answered. One must make certain that the parents understood what was said in the initial meeting in terms of their interpretation of the implications assigned to the diagnosis. ${ }^{16}$

Sometimes an anxious parent may misunderstand the information or miss some important components. Important points should be stressed by repeating them in different ways. Parents' question lists can be answered and new diagnostic and therapeutic issues can be addressed. At this stage, genetic counseling, where appropriate, may have been provided to the family. If it has not been raised, it should be briefly discussed. Concentrate on positive aspects of the management including the appropriate involvement of a multidisciplinary team including physiotherapy, occupational therapy, nutritionist, and those involved in Developmental Medicine. The parents must be assured that additional equipment to assist the child's disabilities, where appropriate, can be provided, e.g., wheelchair, glasses, hearing aids, etc., as well as medications to treat any complications, e.g., sleep disorders, epilepsy, spasticity, etc. The effects of these treatments should be clearly stated as being symptomatic and not curative, in order to prevent false hope of complete neurological recovery.

\section{ADDITIONAL MEDICAL, SOCIAL, AND EMOTIONAL SUPPORT}

The parents should receive adequate medical, social and emotional support. Involvement of other subspecialists as they relate to each specific case (e.g. endocrine, metabolic or genetic consultants, etc.) is important to assure the parents of the adequacy of medical care. Physicians should be open to the concept of a second opinion. When brought up by parents, the physician must not convey the outward appearance of being irritated or personally offended. Many times this idea is brought up under social pressure. The physician should facilitate this process. This facilitation, especially if it is presented as a very welcomed suggestion, will greatly relieve bereaved parents and increase their confidence in you, as the treating consultant. One should attempt to help the family and direct them to the right person who can provide a reliable second opinion. Physicians should also keep a list and have contacts with various local disability foundations and service associations that could benefit the parents and the child. Social support should also be encouraged with the coordination of the case social worker. Parents should be encouraged to show and share their feelings with close family members and friends to strengthen their support group. In the Saudi Arabian society, there is a tendency to keep these issues secret even from the closest family members and friends. Our suggestion is that such issues should be discussed with the family and the parents should be encouraged to contact family support groups. If these are not available, telephone numbers of families with similarly affected children (after obtaining their consent) would be helpful as most parents desire parent-to-parent referral. ${ }^{18}$ The potential powerful positive effect of this latter strategy cannot be over-emphasized. In Saudi Arabia, most parents also benefit from religious and spiritual support with readings from the Holy Book and discussions with eligible scholars.

\section{CONCLuSions}

This paper reviews and details an outline regarding the process of communicating neurological bad news to parents. In summary, physicians must prepare adequately for this process. The skills necessary for breaking bad news well can be acquired through organized undergraduate and postgraduate education, which emphasizes a good working doctor-parent relationship. Neurological bad news should be communicated to both parents as early as possible. Parents prefer the physicians who show a genuine caring attitude, who encourage and allow them to talk, and who show understanding of their emotional responses. The balance between avoiding pessimism, providing hope, and being realistic needs to be maintained throughout the interview. Sensitivity to both informational content and parents'responses and emotional reactions is critical. Subsequent meetings should be arranged to stress important points, update, and answer their ongoing, and indeed often recurrent, questions. Confidence should be conveyed in the parents' ability to cope with and manage the child.

In twenty-first century medicine this part of the "art" of medicine is too often sacrificed in deference to the science of medicine. Such a sacrifice not only contravenes the oath which we all take upon graduation from a Faculty of Medicine but indeed germinates much of the criticism which seems to have arisen towards physicians over the past two or three decades. Many physicians may already follow some of the proposed guidelines. However, hopefully the details, as outlined in the foregoing, will assist practitioners in communicating neurological bad news to parents more effectively and compassionately.

\section{ACKNOWLEDGEMENT}

The authors thank Ms. Eden Castillejo for typing numerous drafts of the manuscript.

\section{REFERENCES}

1. Tadmouri GO, Tadmouri NB. Genetic disorders in Arabs as for OMIM. Neuroscience 1999; 4:1-3.

2. El-Hazmi MAF, Warsy AS. Genetic disorders among Arab populations. Saudi Med J 1996; 17:108-123.

3. Ablon J. Parents' responses to their child's diagnosis of neurofibromatosis 1. Am J Med Genet 2000; 93:136-142.

4. Jurkovich GJ, Pierce B, Pananen L, Rivara FP. Giving bad news: the family perspective. J Trauma 2000; 48:865-870.

5. Chisholm CA, Pappas DJ, Sharp MC. Communicating bad news. Obstet Gynecol 1997; 90:637-639.

6. Nielsen D, Schmidt L. Breaking bad news: experience and attitude of young physicians. Ugeskr Laeger 1997; 159:2862-2866.

7. Weber M, Werner A, Nehring C, Tentrup FJ. Breaking of bad news. Practical advice to physicians for successful communication with patients. Med Klin 1999; 94:453-457.

8. Ptacek JT, Fries EA, Eberhardt TL, Ptacek JJ. Breaking bad news to patients: physician's perceptions of the process. Support Care Cancer 1999; 7:113-120.

9. Vetto JT, Elder NC, Toffler WL, Fields SA. Teaching medical students to give bad news: does formal instruction help? J Cancer Educ 1999; 14:13-17.

10. Garg A, Buckman R, Kason Y. Teaching medical students how to break bad news. CMAJ 1997; 156:1159-1164.

11. Greenberg LW, Ochsenschlager D, O'Donnell R, Mastruserio J, Cohen GJ. Communicating bad news: a pediatric department's evaluation of a simulated intervention. Pediatrics 1999; 103:1210-1217. 
12. Vaidya VU, Greenberg LW, Patel KM, Strauss LH, Pollack MM. Teaching physicians how to break bad news: a 1-day workshop using standardized parents. Arch Pediatr Adolesc Med 1999; 153:419-422.

13. Ungar L, Alperin M, Amiel G, Behrier Z, Reiss S. Breaking bad news: a structured course for primary care physicians. Harefuah 2000; 139:198-202.

14. Fallowfield L. Giving sad and bad news. Lancet 1993; 341(8843):476-478
15. Shields CE. Giving patients bad news. Prim Care 1998; 25:381-390.

16. Ahmann E. Review and commentary: two studies regarding giving bad news. Pediatr Nurs 1998; 24:554-556.

17. Eggly S, Afonso N, Rojas G, et al. An assessment of resident's competence in the delivery of bad news to patients. Acad Med 1997; 72:397-399.

18. Sharp MC, Strauss RP, Lorch SC. Communicating medical bad news: parent's experiences and preferences. J Pediatr 1992; 121:539-546. 